\title{
Can India lead the way in neglected diseases innovation?
}

\author{
Nirmal Kumar Ganguly and colleagues call for a comprehensive policy for neglected diseases \\ research in India to foster innovation in drugs, diagnostics, and vaccines, critical for evolving needs \\ of elimination programmes
}

I ndia is one of the top global funders of research and development (R\&D) into neglected diseases. With a promising scientific base built on the foundation of an expanding science and technology workforce, ${ }^{1}$ the country is well placed to make a substantial contribution to innovation in neglected tropical diseases. A third of new drugs (six out of 18) and two thirds of new vaccines (six of 10) for neglected diseases registered since 2000 have had Indian involvement. Nearly $12 \%$ of drug, diagnostic, and vaccine candidates for neglected diseases in the R\&D pipeline are from India. ${ }^{1}$ The world's first leprosy vaccine was developed in India and is expected to accelerate eradication efforts. ${ }^{2}$

India has successfully eliminated certain infectious diseases-such as guinea worm, trachoma, and yaws-in recent years. ${ }^{3-5}$ Yet, neglected diseases such as leishmaniasis, filariasis, leprosy, snakebite, and soil transmitted helminthic infections still pose a challenge. There persist challenges in the implementation of new technologies and major research gaps. The current model of innovation is driven by market forces and is failing to deliver a steady stream of products that reach patients through adoption into treatment programmes. ${ }^{67}$ Neglected diseases predominantly affect poor and marginalised populations and do not constitute a market that is attractive enough to stimulate private sector investment. As such, the Indian government must step in with appropriate policies and investments to support innovation. In this article, we review existing policies and mechanisms, and propose actions to create an enabling environment for neglected diseases research in India.

\section{Current policy scenario}

A comprehensive policy to foster research and innovation in drug discovery, diagnostics, and vaccine development in neglected tropical diseases is lacking. Box 1 lists relevant policy statements in India in recent years. While political intent and will are expressed in a few, clear operational plans and funding mechanisms are not specified. Consequently, follow-up action is patchy or absent.

No institutional mechanism exists at a national level to identify gaps in neglected diseases research, set priorities, liaise with research institutions, or monitor research output. There is often no coordination between the various funding and research bodies to prioritise the research agenda and minimise duplication.

\section{Not enough funding for product development} India is the fourth largest government funder of neglected diseases research, and the largest among middle income countries. Yet, funding falls far short of requirements. ${ }^{14}$ Few public agencies disburse R\&D grants for neglected diseases in India. ${ }^{15} \mathrm{An}$ analysis of contribution to neglected diseases research globally reveals this shortfall in public funding. The average funding by the Indian Council of Medical Research (ICMR) from 2008 to 2015 was about \$26m (£21m; €23m) per year, while the National
Institutes of Health in the US contributed over $£ 1.3$ bn per year. ${ }^{16}$ Indian pharmaceutical companies have filed few patents for new drugs and innovations compared with those in the US or China, which are investing heavily in innovation. ${ }^{17} \mathrm{~A}$ recent trend with involvement of start-ups in diagnostic innovation ${ }^{18}$ offers promise.

\section{Slow adoption of novel and innovative technologies}

The absence of market intermediaries for commercialisation of products for neglected diseases often results in innovations remaining in laboratories. Few government programmes have supported translational research to facilitate adoption of new drugs and technologies in the real world for treatment and control of neglected diseases. The ICMR has attempted to invite companies to commercialise new technologies such as diagnostic assays, reagents, devices, and vaccines for infectious diseases under a public-private partnership model. It is not clear how well

\section{Box 1: Recent policies on neglected diseases research in India}

- The National Health Policy (2017) sets an ambition to stimulate innovation to meet health needs and ensure that new drugs are affordable for those who need them most, ${ }^{8}$ but it does not specifically tackle neglected diseases

- The National Policy on Treatment of Rare Diseases (2018) includes infectious tropical diseases and identifies a need to support research on treatments for rare diseases. It has not yet prioritised diseases and areas for research funding or how innovation would be supported ${ }^{9}$

- The Science, Technology, and Innovation Policy (2013) does not mention research on neglected diseases ${ }^{10}$

- The Draft National Pharmaceutical Policy (2017) states that one of its objectives is to create an enabling environment to develop and produce innovator drugs, but the policy does not mention drugs for neglected tropical diseases

- The National Biotechnology Development Plan (2015-2020) seeks to encourage the preclinical and clinical development of vaccines against rotavirus, cholera, typhoid, rabies (human (DNA) based), malaria, dengue, tuberculosis, and Japanese encephalitis ${ }^{11}$

- The National Intellectual Property Rights Policy (2016) states that it will encourage publicly funded R\&D institutes and industry to develop affordable drugs for neglected diseases but does not spell out how it will do so. There has been no activity reported in this area ${ }^{12}$

- The Open Source Drug Discovery programme was set up by the Council of Scientific and Industrial Research for new inventions for the prevention, diagnosis, and treatment of common diseases in India. This programme is no longer being funded. ${ }^{13}$ It could have served as a platform to discover new drug targets and drugs for infectious and non-communicable diseases 
this strategy has worked for neglected diseases technologies. ${ }^{19} 20$ The Biotechnology Industry Research Assistance Council funds translational research and has taken up the development of snakebite antivenom, but this is still in early stages.

It is our observation that national programmes for neglected diseases in India tend to delay adoption of Indian innovations. Quite often products developed in India have been accepted outside the country before their adoption at home. For example, the oral rehydration suspension was jointly developed by scientists working in India and Bangladesh ${ }^{21}$ to treat cholera, however it has not been uniformly adopted in these countries. ${ }^{22}{ }^{23}$ An oral cholera vaccine that was tested and manufactured in India and has been approved by the World Health Organisation is not yet included as part of the national programme, thereby limiting access. ${ }^{2425}$ Meanwhile, the vaccine was used in Bangladesh during the Rohingya refugee crisis to prevent cholera outbreaks. ${ }^{2627}$

Box 2 provides an example of innovations in management of visceral leishmaniasis in India and the need for continually evolving strategies. There is no roadmap for carrying out trials for new drugs and incorporating new innovations as part of the national visceral leishmaniasis elimination programme in India. As such, several innovations have not yet been commercialised.

\section{Regulatory bottlenecks}

Schedule Y of the Drugs and Cosmetics Rules in India does not permit phase I clinical trials of drugs or vaccines that have been developed outside India. ${ }^{40}$ This can act as a disincentive to invest in neglected diseases prevailing in, or exclusive to, India. A favourable provision for neglected diseases is built in, however, which states that toxicological and clinical data requirements may be abbreviated, deferred, or omitted for drugs indicated in diseases of special relevance to India. This provision has not yet been deployed.

An expedited regulatory approval process can facilitate rapid adoption of proved drugs and technologies. The Orphan Drug Act in the US and the Orphan Drugs Regulation in Europe provide examples of creating an enabling policy environment that has stimulated development of new drugs for rare diseases. ${ }^{41}$ The priority review voucher (PRV) programme in the US helped promote R\&D for new drugs targeting neglected tropical diseases by supporting expedited regulatory review and thereby potentially allowing drugs to reach the market early. ${ }^{42} 43$
Appropriate safeguards must be built in while developing preferential regulatory approval pathways. ${ }^{44}$ There have been challenges in enabling access to these drugs in the long run. For example, miltefosine, which is used to treat visceral leishmaniasis, was registered by the Food and Drug Administration as an orphan drug in 2014 under the PRV programme and received accelerated regulatory clearance. Yet this has had no impact on improving access. ${ }^{45}$ Furthermore, serious side effects and treatment failures were noted after the drug was introduced on a large scale. ${ }^{46}$

\section{Way forward}

It is time for India to establish a comprehensive policy on neglected diseases that paves the way for greater funding and mechanisms to support research and innovation. Box 3 lists the essential elements. A unified programme on neglected diseases encompassing research and elimination measures is likely to have a greater impact in prioritising the matter in the health agenda and streamlining efforts towards disease elimination. Creating an enabling environment for research and innovation will be crucial if India is to achieve the target set in sustainable development goal 3.3 to end epidemics of neglected tropical diseases by 2030 .

Box 2: Innovation in visceral leishmaniasis elimination in India

\section{Drugs}

- Increasing treatment failures using miltefosine prompted the development of a new treatment regimen for visceral leishmaniasis. New drug trials were conducted through a partnership between government research institutes in India and the Drugs for Neglected Diseases initiative, and led to development of a new treatment-liposomal amphotericin B (AmBisome). A single intravenous infusion of liposomal amphotericin B was found to be effective in treating visceral leishmaniasis ${ }^{28}$ and is now recommended as first line treatment in the national programme in India. ${ }^{29}$ This drug was subsequently tested and introduced in Bangladesh and Nepal

- Cases of resistance to miltefosine and liposomal amphotericin B have been reported. New drug regimens need to be developed periodically to overcome resistance

\section{Diagnostics}

- Indian labs have played a significant role in the development of rK39 and rKE16, which have demonstrated high sensitivity and specificity, good reproducibility, and, most importantly, are heat stable for tropical countries like India. However, the sensitivity is more variable in sample panels from east Africa and South America. ${ }^{30}$ A diagnostic probe has been developed in Kolkata but is yet to be commercialised ${ }^{31}$

Vaccine development

- Vaccines against visceral leishmaniasis are in different stages of development ${ }^{32-34}$ Financial support provided by the Japanese Global Health Innovative Technology Fund has played a vital role ${ }^{35}$

- A patented innovation from India shows that HbR-DNA from the leishmania parasite coding for $\mathrm{HbR}$ protein or fragments thereof is a marker for diagnosis of leishmaniasis. It is immunogenic in humans and could be a vaccine candidate ${ }^{36}$

\section{Vector control}

- Research into vector ecology, mathematical modelling of disease transmission, and interventions such as nets treated with insect repellent is essential to control disease transmission. The National Vector Borne Disease Control Programme implements the integrated vector management programme for eradication of neglected diseases and supports research in this area ${ }^{37}$

- Indoor residual spraying of insect repellent is carried out in endemic districts as part of leishmania control measures. Innovative devices-such as a hand compression pump that is easier to operate, more effective, and less costly than the stirrup pump used in the programme-are being studied

- Development of disruptive technologies for vector control using nature's own mechanisms is the new norm. The bacterium Wolbachia exploits the host's innate immunity to establish a symbiotic relationship with the dengue vector mosquito Aedes aegypti ${ }^{38}$ and is being tested for dengue prevention. Using a similar approach, Wolbachia is being tested in the control of filarial nematodes ${ }^{39}$ 


\section{Box 3: Essential elements of a comprehensive neglected disease policy}

\section{Funding}

- Earmark a proportion of public funds for neglected diseases research and innovation ${ }^{47}$

- Funding for translational research to support product development.

- The stress on developing internal resources for laboratories has made institutions and scientists shift their research onto diseases with potential market value. Guaranteed public funding would correct this imbalance

\section{Regulation}

- Develop mechanisms to facilitate priority regulatory pathways for innovations in neglected diseases

- Capacity building and strengthening of regulators, including institutional ethics committees, in handling regulatory process for neglected diseases

- Facilitate early adoption of innovations proved effective into national disease treatment programmes. This would incentivise innovation and provide assurance to industry that the products developed will have a market

\section{Research environment}

- A National Observatory on Biomedical R\&D to prioritise, coordinate, and monitor research output, including on neglected diseases, is needed. Such an institutional mechanism would enable efficient allocation of resources and allow policy makers, funders, researchers, and patient groups to identify areas of public investment and existing gaps, and suggest improvements

- Creating common repositories of biological samples and other materials accessible to researchers, industry, and regulators would facilitate innovation. The absence of a pan-India surveillance data repository on pathogenic strains of neglected diseases poses a hindrance to innovation for vaccines

- Defining specificity and sensitivity standards for diagnosis of neglected diseases would facilitate diagnostic innovation and help regulatory authorities evaluate these

- Alternative approaches to R\&D based on the principles of open innovation and product development partnerships must be explored.

- A comprehensive national surveillance database for neglected diseases is essential to monitor trends across the country. This could be achieved by strengthening the existing integrated disease surveillance programme. The use of molecular diagnostics at point of care coupled with information technology is the future for robust surveillance. Global positioning systems and mobile technology to track migratory populations are being employed in disease surveillance in Sri Lanka and in the Mekong delta region of SEARO countries, and need to be tested in India ${ }^{48}$

- The evolving areas of genomics, transcriptomics and proteomics research can provide a better understanding of the modes of infection and treatment options. More drug and vaccine targets can be identified, and it would provide impetus to biotechnological research and industry.

Contributors and sources: ZT, GKS, KMG, and NKG contributed equally to the manuscript. GKS and ZT carried out the literature search on neglected tropical disease (ND) research. KPG looked at the trade agreements and their implications on R\&D in India. NKG provided SEARO and WHO policies on ND and their effect on national elimination programmes. GKS carried out a search for national health programmes as well relevant scientific articles on innovations. Indian government policies on science promotion, as well reports on NDs elimination published by international agencies such as WHO and SEARO were also obtained.

Competing interests: We have read and understood BMJ policy on declaration of interests and have no relevant interests to declare.

Provenance and peer review: Commissioned; externally peer reviewed.

This article is one of a series commissioned by The BMJ in collaboration with the Drugs for Neglected Diseases initiative (DNDi). The BMJ retained full editorial control over external peer review, editing, and publication. Open access fees are funded by the DNDi, Geneva.

Zakir Thomas, commissioner of income tax former project director ${ }^{1,2}$

Gautam Kumar Saha, scientific associate

Kappoori Madhavan Gopakumar, senior researcher and legal adviser

Nirmal Kumar Ganguly, president ${ }^{3,5}$

${ }^{1}$ Central Board of Direct Taxes, Department of Revenue, Ministry of Finance, New Delhi, India

${ }^{2}$ Open Source Drug Discovery, India

${ }^{3}$ Apollo Hospitals Educational and Research Foundation, New Delhi, India

${ }^{4}$ Third World Network, Geneva, Switzerland Indian Council of Medical Research, India
Correspondence to: N Kumar Ganguly ganguly.nk@aherf.net

\section{(@) (1) $\Theta$ OPEN ACCESS}

This is an Open Access article distributed in accordance with the Creative Commons Attribution Non Commercial (CC BY-NC 4.0) license, which permits others to distribute, remix, adapt, build upon this work non-commercially, and license their derivative works on different terms, provided the original work is properly cited and the use is non-commercial. See: http://creativecommons.org/ licenses/by-nc/4.0/.

\section{Check for updates}

1 Moran M, Chapman N, Chowdhary V, et al. The role of Team India in global health R\&D. Policy Cures. March 2015. http://policycures.org/downloads/Indian\%20 Report.pdf.

2 Narayan P. World's first leprosy vaccine, developed in India, to go on trial. Times of India. 20 August 2016. http://timesofindia.indiatimes. com/articleshow/53788765.cms?utm source $=$ contentofinterest\&utm_medium $=$ text\&utm campaign $=$ cppst.

3 Ministry of Health and Family Welfare. Chapter 5 disease control programmes. https://mohfw.gov.in/ sites/default/files/56478563254566332556.pd

4 Sharma R. India eradicates guinea worm disease. BMJ 2000;320:668

5 World Health Organization. India's triumph over yaws adds momentum to global eradication. 2016. www. searo.who.int/mediacentre/releases/2016/1629/en.

6 Malaria Consortium. Vector control: the untapped potential for neglected tropical diseases. September 2017. www.malariaconsortium.org/resources/ publications/1022/vector-control-the-untappedpotential-for-neglected-tropical-diseases.

7 WHO, Department of Control of Neglected Tropical Diseases. Integrating neglected tropical diseases in global health and development Fourth WHO report on neglected tropical diseases. 2017. www.who.int/ neglected_diseases/resources/9789241565448/en.

8 Open Government Data Platform India. National health policy, goals to be achieved https://data.gov. in/keywords/national-health-policy.

9 Ministry of Health and Family Welfare, Department of Health and Family Welfare. Rare diseases. https:// mohfw.gov.in/diseasealerts/rare-diseases.

10 Ministry of Science \& Technology. Science, technology and innovation policy 2013. www. dst.gov.in/sites/default/files/STI\%20Policy\%20 2013-English.pdf.

11 Department of Biotechnology, Ministry of Science and Technology. National biotechnology development plan 2015-2020. www.dbtindia. nic.in/wp-content/uploads/DBT_Book-_29december 2015.pdf.

12 Department of Industrial Policy and Promotion. National IPR policy. http://dipp.nic.in/policies-rulesand-acts/policies/national-ipr-policy.

13 Abrol D. The wrong incentive. Econ Polit Wkly 2016;51:24. www.epw.in/journal/2016/24/ commentary/wrong-incentive html.

14 Chapman N, Doubell A, Oversteegen L, et al. Neglected disease research and development: reflecting on a decade of global investment. 2017. http://policycuresresearch.org/downloads/Y10_G FINDER full report.pdf.

15 World Health Organization. Prioritising R\&D needs is element 1 of WHO's Global Strategy and Plan of Action. 2011. www.who.int/phi/publications/ Global_Strategy_Plan_Action.pdf.

16 Chapman N, Abela-Oversteegen L, Doubell A, Chowdhary V, Gurjav U, Ong M. Neglected disease research and development: a pivotal moment for 
global health. 2017. www.vaccinefoundation.org/ files/GF_report16_all_web.pdf.

17 World Intellectual Property Organization. China drives international patent applications to record heights: demand rising for trademark and industrial design protection. 21 March 2018. www.wipo.int/ pressroom/en/articles/2018/article_0002.html.

18 Saxena M, Sonkar S, Sarkar S. Water soluble nano carbons arrest the growth of mosquito. RSC Advances 2013. doi:10.1039/c3ra44100h.

19 ICMR seeks interest for commercializing its technologies. Biospectrum. 25 March 2013. www. biospectrumindia.com/news/18/913/icmr-seeksinterest-for-commercializing-its-technologies.html.

20 Indian Council for Medical Research. Technology for collaboration. www.icmr.nic.in/technology-forcollaboration.

21 Bhattacharya SK. History of development of oral rehydration therapy. Indian J Public Health 1994;38:39-43.

22 Cash RA. Why is every country not primed to use oral rehydration therapy to treat cases of diarrhoea?WHO South East Asia I Public Health 2012:1:113-5. doi:10.4103/2224-3151.206907

23 Bhattacharya SK. History of development of oral rehydration therapy. Indian J Public Health 1994;38:39-43.

24 Sur D. Challenges in new vaccine introduction in a national program in India. Indian J Public Health 2016;60:171-5. doi:10.4103/0019557X.188995

25 Kanungo S, Sen B, Ramamurthy T, et al. Safety and immunogenicity of a live oral recombinant cholera vaccine VA1.4: a randomized, placebo controlled trial in healthy adults in a cholera endemic area in Kolkata, India. PLoS One 2014;9:e99381. doi:10.1371/journal.pone.0099381

26 Saha A, Khan A, Salma U, et al. The oral cholera vaccine Shanchol ${ }^{T M}$ when stored at elevated temperatures maintains the safety and immunogenicity profile in Bangladeshi participants. Vaccine 2016;34:1551-8. doi:10.1016/j.vaccine.2016.02.020

27 World Health Organization. Oral cholera vaccination campaign kicks off at Rohingya camps in Bangladesh. October 2017. www.searo.who.int/mediacentre/ releases/2017/1668/en.

28 Sundar S, Singh A, Rai M, Chakravarty J. Singledose indigenous liposomal amphotericin B in the treatment of Indian visceral leishmaniasis: a phase 2 study. Am I Trop Med Hyg 2015;92:513-7. doi:10.4269/ajtmh.14-0259

29 Drugs for Neglected Diseases initiative. New VL treatment in Asia. www.dndi.org/diseases-projects/ portfolio/new-vl-treatments-asia.

30 WHO. Visceral leishmaniasis rapid diagnostic test performance. 2011. www.who.int/tdr/publications/ documents/vl-rdt-evaluation.pdf.

31 Bandyopadhyay S, Chatterjee M, Pal S, et al. Purification, characterization of $\mathrm{O}$-acetylated sialoglycoconjugates-specific lgM, and development of an enzyme-linked immunosorbent assay for diagnosis and follow-up of indian visceral leishmaniasis patients. Diagn Microbiol Infect Dis 2004:50:15-24. doi:10.1016/j. diagmicrobio.2004.04.014

32 Avishek K, Kaushal H, Gannavaram S, et al. Gene deleted live attenuated Leishmania vaccine candidates against visceral leishmaniasis elicit proinflammatory cytokines response in human PBMCs. Sci Rep 2016;6:33059. doi:10.1038/srep33059

33 TDR, the Special Programme for Research and Training in Tropical Diseases. Vaccine development: leishmaniasis. www.who.int/tdr/research/ progress/9900/vaccine dev leish/en.

34 Mologen AG. Press release: presentation of DNA vaccine against leishmaniasis at IMED 2014. 2014 www.mologen.com/en/investor-relations-press/ news/press-releases/2014/detail-view/article/ mologen-praesentiert-dna-impfstoff-gegenleishmaniose-auf-der-imed-2014.html.

35 GHIT Fund accelerates promising efforts to find new treatments, vaccines and diagnostics. 31 October 2017. Eureka Alert. www.eurekalert.org/ pub_releases/2017-10/b-gfa103117.php.

36 Mukhopadhyay A, Syamal R, Gupta D, Guha $R$, Rastogi R. Hemoglobin receptor as novel vaccine for leishmaniasis. WO patent application, W02014184797A2. https://patents.google.com/ patent/WO2014184797A2

37 Srivastava PK, Sharma RS, Sharma SN, et al. Integrated vector management: policy and implementation under national vector borne disease control programme. India I Commun Dis 2014; 46:46-50.

38 Pan X, Pike A, Joshi D, et al. The bacterium Wolbachia exploits host innate immunity to establish a symbiotic relationship with the dengue vector mosquito Aedes aegypti. ISME / 2018:12:277-88 doi:10.1038/ismej.2017.174

39 Slatko BE, Taylor MJ, Foster JM. The Wolbachia endosymbiont as an anti-filarial nematode target. Symbiosis 2010;51:55-65. doi:10.1007/s13199. 010-0067-1

40 Central Drugs Standard Control Organization. Drugs and cosmetics rules, 1945. http://cdsco.nic.in/ html/D\&C Rules_Schedule_Y.pdf.

41 McCabe C, Stafinski T, Menon D. Is it time to revisit orphan drug policies?BM/ 2010;341:c4777. doi:10.1136/bmi.c4777

42 Mikami K. Orphans in the market: the history of orphan drug policy. Social History of Medicine. 27 November 2017. doi:hkx098.

43 Robertson AS, Stefanakis R, Joseph D, Moree M. The impact of the US priority review voucher on private-sector investment in global health research and development. PLoS Negl Trop Dis 2012;6:e1750. doi:10.1371/journal. pntd.0001750

44 Herder M. What Is the Purpose of the Orphan Drug Act?PLoS Med 2017;14:e1002191. doi:10.1371/ journal.pmed.1002191

45 Sunyoto T, Potet J, Boelaert M. Why miltefosine-a life-saving drug for leishmaniasis-is unavailable to people who need it the most. BMJ Glob Health 2018:3:e000709 doi:10.1136/ bmigh-2018-000709

46 Ostyn B, Hasker E, Dorlo TPC, et al. Failure of miltefosine treatment for visceral leishmaniasis in children and men in South-East Asia. PLOS One 2014;9:e100220. doi:10.1371/journal. pone. 0100220

47 World Health Organization. Research and development to meet health needs in developing countries: strengthening global financing and coordination. 5 April 2012. www.who.int/phi/CEWG Report_5_April_2012.pdf.

48 World Health Organization, Regional Office for South Asia. Mobile and migrant populations and malaria information systems. 2015. http://apps.who. int/iris/bitstream/handle/10665/204343/SEAMAL-279.pdf.

Cite this as: BMJ 2019;364:k5396

http://dx.doi.org/10.1136/bmj.k5396 